\title{
Analysis of Factors Affecting College Students' Online Entrepreneurship Based on VAR Model
}

\author{
Jiang Yongchun, Wang Fengjiao \\ Qingdao Huanghai College \\ Qingdao, Shandong 266427
}

\begin{abstract}
With the development of the information society, online entrepreneurship has gradually become the first choice for college students. Although there are many advantages such as low cost, flexible marketing method and low entry threshold, there are still many risks for college students. Based on the original data obtained from questionnaires, this paper established a risk analysis model based on VAR., the authors analyzed the influencing factors and degree of online entrepreneurship for college students so as to provide scientific references for college students to control the risks of online entrepreneurship.
\end{abstract}

Keywords-VAR Model; Online Entrepreneurship; The Risk Assessment

\section{INTRODUCTION}

The latest figures released by the Ministry of Education showed that the number of graduates in 2018 was nearly 8.2 million, the highest in nearly 10 years, which means the situation of college students employment and entrepreneurship is becoming grimmer. With the development of diversified and globalized economy, online entrepreneurship has entered the vision of college students and aroused great attention from the government. Since it is an effective way to relieve the pressure of employment, governments at all levels have actively launched the policy of helping college students to start businesses online; Colleges and universities are paying more and more attention to online entrepreneurship education, too. However, the rate of online entrepreneurship of college students is still at a low level in our country at present [1-2].

Online entrepreneurship has become the first choice for college students for many favorable conditions, such as policy encouragement and support from the society, government, and university departments, lower thresholds, greater market access and higher recognition among college students. However, online entrepreneurship may influenced by many sides of factors, which means that there would be different kinds of risks for college students who start business online. In order to provide a reliable reference for college students to control the risk of online entrepreneurship, the author made a survey, from which got 487 validated from 500 questionnaires, 97\% effective [3-4], to acquire the initial data. Then, based on these data, the author analyzed the influencing factors of online entrepreneurship and their degree with the help of VAR-based risk analysis model.

\section{ESTABLISHING PRINCIPLES AND RESEARCH METHODS OF VAR MODEL}

\section{A. The VAR Model}

The VAR model (vector autoregressive model) is based on the statistical properties of the data, and has strong spatial relationship analysis ability for time series data. In other words, the model can not only analyze the correlation between variables, but more importantly, can analyze the impact of variables on their own and other variables before and after the sequence data. The expression is as follows:

$$
\mathrm{Y}=\mathrm{A} 1 \mathrm{Y} 1+\ldots+\mathrm{AnYn}+\mathrm{BXn}+\mathrm{e}
$$

$\mathrm{Y}$ is an endogenous variable vector, $\mathrm{X}$ is an exogenous variable vector, A, An and B are coefficient matrices to be evaluated, and $\mathrm{e}$ is the error vector.

\section{B. Establishing VAR Model for Influencing Factors of \\ College Students' Online Entrepreneurship}

College students are a special group, who dare to challenge and take risks. They have strong independence and strong learning and applying ability on network technology. Therefore, online entrepreneurship has become a new way of employment and entrepreneurship for college students. However, at the same time, there are many traps and risks for college students to start their online business, and the success rate of online entrepreneurship is also very low. Generally speaking, the main factors affecting college students' online entrepreneurship include social environment (SN), self-management ability (MN), capital (ZN), laws and regulations on internet contents and network security (LN), web technology (IN), etc. Taking these aspects as independent variables, the VAR model is established to study the influence of each factor, as shown in figure 1. Here follows a brief introduction to each aspect:

\section{1) The Social Environment Factor (SN)}

The external risks of online entrepreneurship for college students are mainly reflected in the lack of insight ability to commodity market, and the drawbacks in doing market research on a certain commodity in the early stage of starting a business. Therefore, it is difficult to grasp the latest information and development trends in the network commodity market. 


\section{2) Self-management Ability Factor (MN)}

College students do not have a sophisticated management capability. They are lack of management experience, not good at practice, and lack of recognition of the society. All these make it difficult for them to handle the problems properly during the operation and management of the network.

\section{3) Capital Factor (ZN)}

Although college students do not need a lot of money to start an online business, they often encounter various problems such as insufficient funds and tight finances in actual network operations.

4) Laws and Regulations on Internet Contents and Network Security Factor (LN)

At present, there are many kinds of network traps. College students should also raise their vigilance, not only abide by the national network laws and regulations, but also pay attention to the network payment security transactions, information security and so on.

\section{5) Web Technology Factor (IN)}

College students, to some extent, are familiar with the network, but most of them lack of professional technical abilities. For instance, they may lack of the ability of website design and beautification, system software installation and debugging, commodity decoration and design, etc.

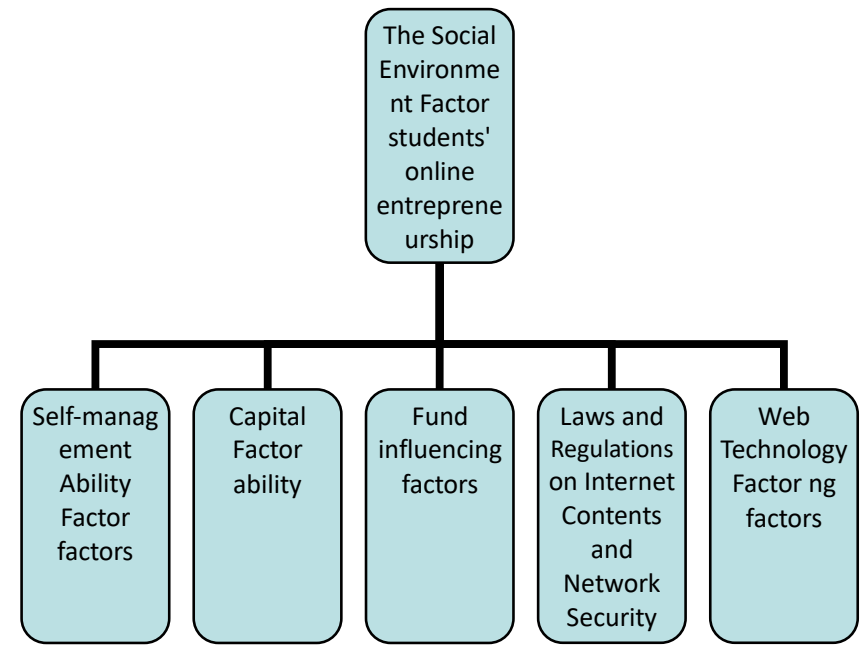

Fig. 1 Factors influencing college students' online entrepreneurship

Based on the above factors, the specific model of VAR can be given as follows:

$$
Y_{k}=M+\sum_{i=1}^{n} A_{i} \cdot Y_{k-i}+\delta
$$

In which, $\mathrm{Yk}=[\mathrm{SN}, \mathrm{MN}, \mathrm{ZN}, \mathrm{LN}, \mathrm{IN}] \mathrm{t}$ represents the spot value of independent variable and dependent variable; I is the number of lag periods, $\mathrm{A}$ is the coefficient matrix, and $\delta=[\delta 1, \delta 2, \delta 3, \delta 4, \delta 5] \mathrm{k}$ is the stochastic disturbance of the regression equation. Reflections can be easily found from the regression equation. On the one hand, the stochastic disturbance $\delta$ reflects the influence on the online entrepreneurship of college students of a series of favorable treatment from national and local governments and from education departments; on the other, the lag $\mathrm{i}$ is a reliable indicator of the expectation of college students on online entrepreneurship.

\section{RESULtS ANALYSIS}

\section{A. Vector autoregressive estimation}

Through the vector autoregressive estimation of VAR model, the results can be showed in table 1 :

TABLE I VECTOR AUTOREGRESSIVE ESTIMATION

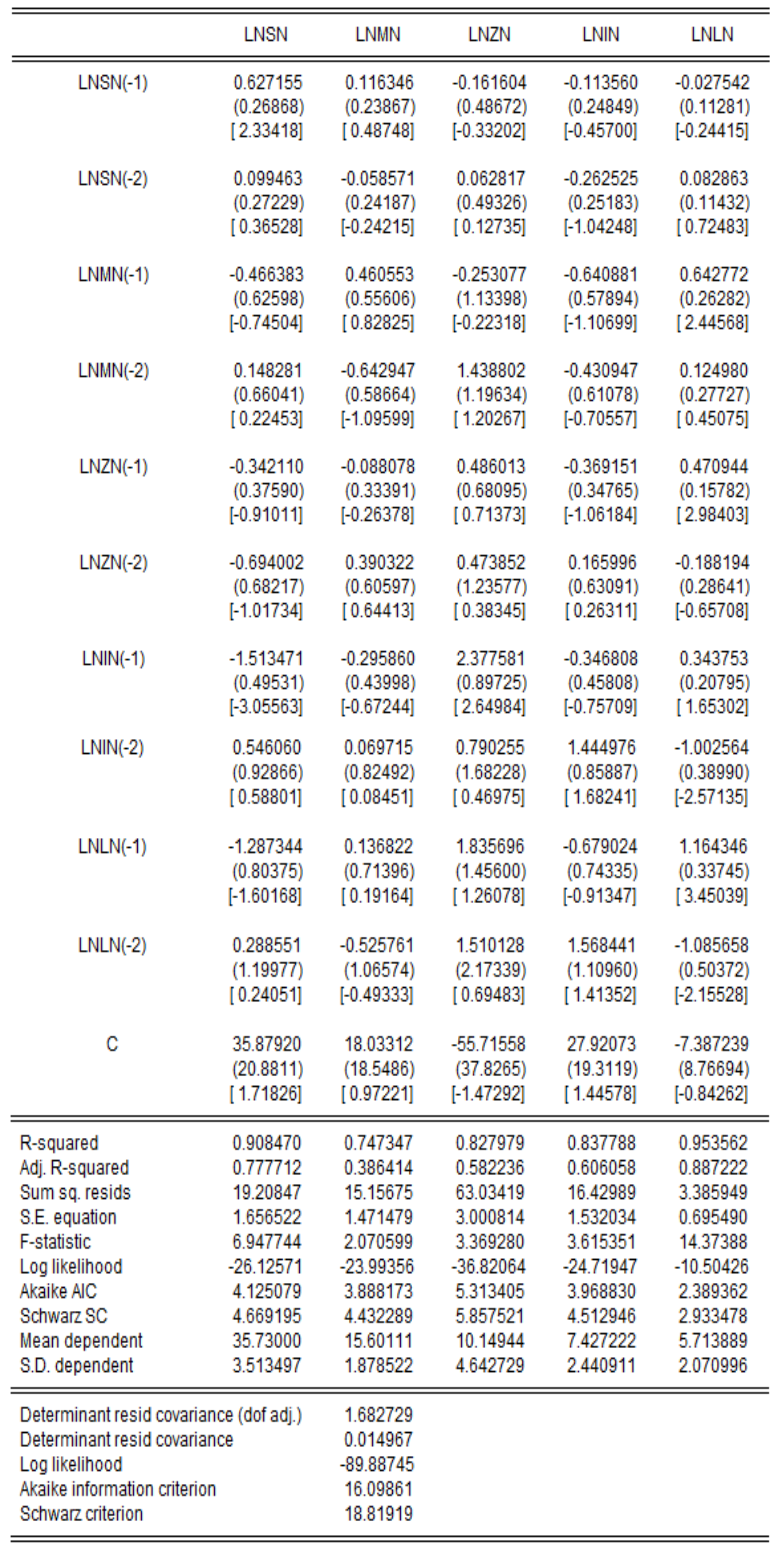

From the output of the VAR model in table 1, we can get the conclusion that:

Among the factors affect online entrepreneurship, the estimated parameters of their self-management ability factor and capital factor are 0.607 and 0.664 , respectively, and the 
significance level is obviously very high. From the regression results, the standard regression statistic of each factor can also be obtained, and the value of the standard regression statistic indicates that the equation fits the dependent variable well. The test value of $F$ is relatively large, indicating that a significant interpretation of the equation. Referring to the rules of SIC and $\mathrm{SC}$, we find that the values of SIC and SC are relatively small, which indicates that the determination of lag order is reasonable.

\section{B. Impulse response function analysis}

By analyzing the impulse response function of response variables, as shown in figure 1. we can get the information that: $\mathrm{ZN}$ has the greatest influence on college students, especially in the early stage of entrepreneurship; the influence of SN and IN is also obvious at the early stage but they tend to be stable later; The influence of LN is relatively small, while it runs through the online entrepreneurship.

Response to Cholesky One S.D. Innovations ?2 S.E.
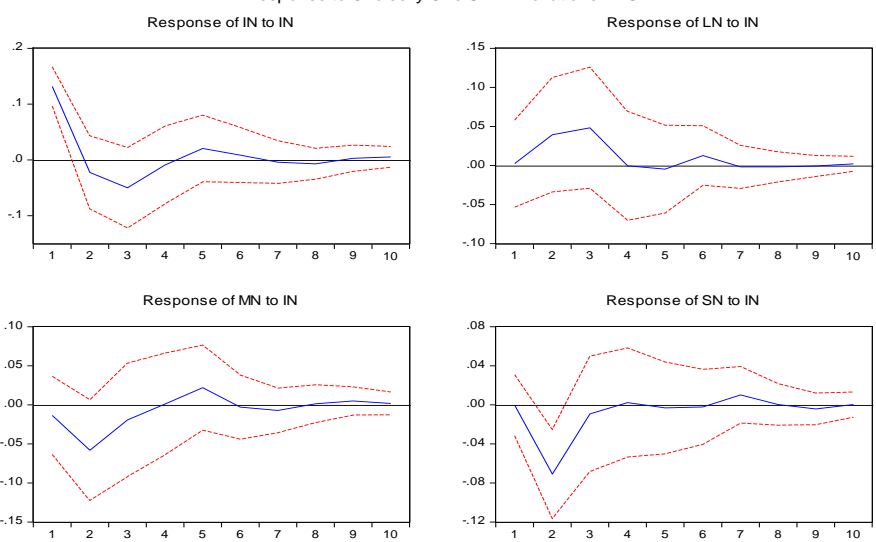

Response of ZN to IN

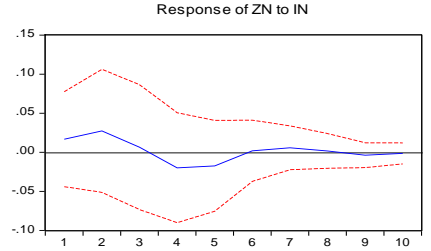

Fig. 2 Impulse response function

\section{Analysis of Variance decomposition}

By analyzing the variance decomposition of the five variables, it is clear that the factor of $\mathrm{ZN}$ has a relatively small impact on the online entrepreneurial; the factors of $\mathrm{MN}$ and IN runs through the whole process of the entrepreneurship and is on rise; the factors of $\mathrm{SN}$ and $\mathrm{LN}$ tend to be stable.

\section{CONCLUSION}

Based on the questionnaire, this paper presents five factors affecting college students' online entrepreneurship and constructs the VAR model through the concrete analysis of these factors. Through the analysis, it can be concluded that social and capital factors have a great impact on the early stage of online entrepreneurship; Self-management ability and network technology factors play an important role in the process of online entrepreneurship; And the security of various network laws and regulations are also need attention when facing with network resources. Therefore, college students should improve the ability to assess and analyze the risks of starting a business online in order to avoid risks in time and strive for success.

\section{REFERENCES}

[1] Wangdong-hui. The Research and Analysis of College Students' Online Entrepreneurship Risks [J]. Modern Enterprise Education, 2009 (6).

[2] Liuhai-bing. Analysis of the Factors Affecting China's Consumer Price Index Based on the VAR Model [J]. Journal of Shandong University of Finance (bimonthly), 2010 (6).

[3] Chenjun-yi. Analysis of College Students' E-commerce Business Risks [J]. Inner Mongolia: Inner Mongolia Science and Technology and Economy, 2012 (8).

[4] Chenghe-ping. Research and Analysis of College students' Network Business Risks and Countermeasure [J]. Financial Times, 2011 (10). 